\title{
Geologiens Dage 2006 - GeoSites - vigtige brikker i Jordens historie
}

\section{Af Koordinationsgruppen for Geologiens Dage}

Geologiens Dage 2006 afholdes landet over lørdag den 30. september og søndag den 1. oktober. Der er 56 tilbud om ture og oplevelser i vores dejlige Danmark.

Planeten Jorden forandrer sig hele tiden, og det har den gjort siden den blev dannet for $4 \frac{1}{2}$ milliarder år siden. Jordskælv, vulkanudbrud, oversvømmelser og jordskred er voldsomme geologiske hændelser, der har givet store og pludselige ændringer af jordoverfladen. Til de mere undseelige processer, der omformer landskabet, hører det strømmende vand i åen, der gnaver i brinken, eller vinden, der flytter rundt på sandet. Dertil kan føjes tiden som geologisk faktor. Afrika og Sydamerika glider fra hinanden med en hastighed på flere centimeter om året. På 200 millioner år er det blevet til et helt ocean.

\section{Et puslespil med mange brikker}

Vi mennesker er helt afhængige af jordklodens ressourcer. Kender vi den geologiske historie, og forstår vi de tilhørende processer, kan vi finde, udnytte og beskytte ressourcerne på en fornuftig og langsigtet måde. Vi skal hele tiden finde nye grundvandsressourcer, mere olie, gas, kul og malme, men det skal ske på en bæredygtig måde. I den mere beskedne ende har vi behov for ler, sand og grus til vore huse, veje, broer mv. Og vi skal sørge for, at bygninger står på et stabilt grundlag, så de ikke slår revner eller styrter sammen.

Den geologiske historie er et puslespil, hvor mange brikker stadig mangler at blive fundet. Det er geologens arbejde at indsamle små og store brikker og lægge dem på rette plads. Lagene i en kystklint og landskabets form er brikker i den geologiske historie, der kan lede til værdifulde grus- eller lerforekomster. Fossiler i dybhavsboringer leder geologen på sporet af olie. Geologiske undersøgelser, der er med til at skabe et samlet billede af Jordens historie, ender aldrig, for naturen viser sig næsten altid mere sammensat end forventet, og der opstår hele tiden behov for ny viden.

\section{GeoSites}

GeoSites er lokaliteter, der fortæller om

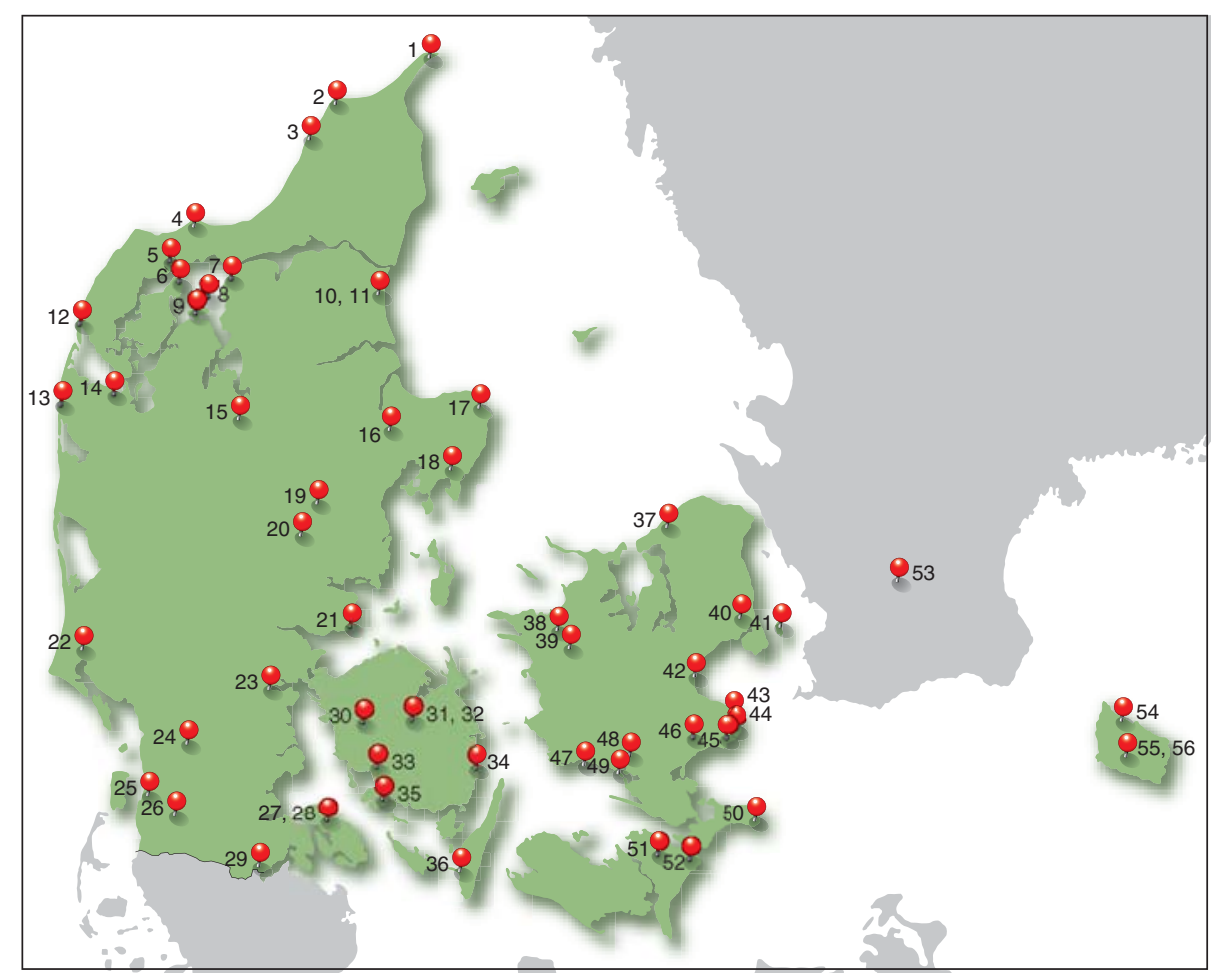

Lokaliteternes placering. (Grafik: Annabeth Andersen, GEUS)

Jordens historie. Det er de store og vigtige brikker i puslespillet. De har international betydning og findes spredt over hele jordkloden. Også i Danmark findes betydningsfulde geologiske lokaliteter. Efter en nøje afvejning gennem længere tid er en række af disse lokaliteter udvalgt som kandidater til danske GeoSites. I slutningen af 2006 indleverer Danmark en liste over kandidaterne til en europæisk organisation. Geologiens Dage 2006 er derfor en oplagt lejlighed til at fremvise et udpluk af disse mulige GeoSites til alle interesserede og samtidig fortælle om, hvorfor netop de er udvalgt. Ca. 25 GeoSites er repræsenteret i programmet for Geologiens Dage. Programmet ses nedenfor. Mødested og anden info findes på naturnet.dk.

\section{Praktiske oplysninger}

De fleste ture er tilrettelagt for deltagere i alle aldre. En del ture er dog ikke egnede for gangbesværede. Hvor intet andet er nævnt er arrangementerne gratis, enkelte kræver tilmelding/betaling. Praktisk påklædning og fodtøj/gummistøvler anbefales. Færdsel langs skrænter, klinter og i råstofgrave sker på eget ansvar. Har du spørgsmål, så henvend dig til turens kontaktperson, arrangør eller eventuelt til koordinatorerne. Da emnet er geologi, kan det være en god idé at medbringe graveske, kniv eller lup på turene

\section{Skagens Oddes dannelse}

Skagens Odde er en GeoSite-kandidat. Turleder: Eigil Torp Olesen

Dato: 30. september. Tidspunkt: 14.00-17.00

2. Stenene på stranden ved Hirtshals Klint Turleder: Henrik Arildskov

Dato: 1. oktober. Tidspunkt: 10.00-14.00

\section{Kystklinter og klitter ved Lønstrup} Lønstrup Klinter er en GeoSite-kandidat. Turleder: Geolog Keld Rømer Rasmussen Dato: 1. oktober. Tidspunkt: 10.00-13.00

\section{Bulbjerg - geologi og kultur}

Turleder: Skovfoged Thorbjørn Nørgaard Dato: 1. oktober. Tidspunkt: 13.00-15.00

\section{Kjølby Gård - salt og dinosaurer} Kjølby Gård er en GeoSite-kandidat Turleder: Geolog Georg Stenstrop Dato: 1. oktober. Tidspunkt: 13.00-15.00

\section{Med lup på Feggeklit}

Feggeklit er en GeoSite-kandidat.

Turledere: Poul Søby Nielsen og Henrik Madsen

Dato: 30. september. Tidspunkt: 13.00-15.00

\section{6a. Moler Museet}

Dato: 30 . september og 1 . oktober 
Åbent: $12.00-16.00$

\section{Find fossiler ved Løgstør}

Turledere: Tommy Sørensen og Susanne Schmidt

Dato: 30. september. Tidspunkt: 13.00-16.00

\section{Sten for store og små på Livø}

Turledere: Ivar Høst og Lars Wachmann

Dato: 1. oktober. Tidspunkt: 11.30-16.00

\section{Kæmpe vulkanudbrud - spor på Fur} Molersbassinet er en GeoSite-kandidat. Turledere: Geolog Bo Schultz og Rene Sylvester

Dato: 30 . september og 1. oktober Tidspunkt: 14.00

\section{9a. Fur Museum}

Dato: 30. september og 1. oktober

Åbent: $12.00-16.00$

\section{Lille Vildmose}

Lille Vildmose er en GeoSite-kandidat. Turleder: Geolog og botaniker Bent Odgaard Dato: 30. september. Tidspunkt: 10.00-13.00

\section{På kanten af Lille Vildmose}

Lille Vildmose er en GeoSite kandidat. Turleder: Naturvejleder Tommy Jensen Dato: 1. oktober. Tidspunkt: 10.00-16.00

\section{Vestkysten fra Agger til Lodbjerg} - hvor ny og gammel geologi mødes Turleder: Geolog Jørgen Dahlgaard Dato: 30. september. Tidspunkt: 13.00-15.00

13. Bovbjerg profilet, tværsnit af en randmoræne

Bovbjerg er en GeoSite-kandidat.

Turleder: Geolog Holger Prahm

Dato: 30. september. Tidspunkt: 13.00-14.30

\section{Hvad isen bragte til Remmer Strand}

Turleder: Peder Flansmose

Dato: 1. oktober. Tidspunkt: 13.00-16.00

\section{Skelhøje}

Skelhøje er en GeoSite-kandidat.

Turledere: Geolog Lars Kristiansen og

Benny Ragner

Dato: 30 . september. Tidspunkt: $14.00-16.30$

\section{Lergrav på Ølst Bakke - Maxit}

Ølst Bakke lergrav er en GeoSite-kandidat. Turleder: Geolog Ole Bjørslev Nielsen Dato: 1. oktober. Tidspunkt: 10.00-13.00

\section{Kalkbankerne ved Karlby og Sang-} strup Klinter

Karlby Klint er en GeoSite-kandidat. Turledere: Geolog Erling Fuglsang Nielsen og konservator Søren Bo Andersen Dato: 1. oktober. Tidspunkt: 13.00-16.00

\section{I isens fodspor på Mols}

Molslandet er en GeoSite-kandidat. Turleder: Geolog Jens Østerby Hansen

Dato: 1. oktober. Tidspunkt: 10.00-14.00

\section{Gudenådalens dannelse}

Gudenå-systemet er en GeoSite-kandidat. Turleder: Geolog Morten Kjærgaard Dato: 1. oktober. Tidspunkt: 10.00-12.30

\section{Stendag på Klostermølle}

Dato: 30 . september. Tidspunkt: 13.00-17.00

21. Albæk Hoved - fedt ler og flotte farver Albæk Hoved er en GeoSites-kandidat. Turleder: Kai Ingemann Schnetler Dato: 1. oktober. Tidspunkt: 10.00-13.00

22. Besøg en stensliber og stensamler i det sydvestjyske

Dato: 1. oktober. Tidspunkt: 10.00-16.00

Arrangør: Sven Rasmussen, Havværk

\section{Udstilling af fossiler fra Kridttiden i} Kolding

Udstiller: Amy Lewring

Dato: 30 . september og 1. oktober

Tidspunkt: Lørdag 10.00-13.00, søndag $13.00-16.00$

24. Kan man fange hvaler i Gram med en skruetrækker?

Gram Lergrav er en GeoSite-kandidat. Turleder: Museumspædagog Martin Abrahamsson

Dato: 1. oktober. Tidspunkt: 14.00-16.00

24a. Museum Sønderjylland, Naturhistorie og Palæontologi

Dato: 30 . september og 1. oktober

Åbent: 13.00-16.00

25. Vadehavet mellem istidslandskaber og klit-/marsk-ørækken

Vadehavet er en GeoSite-kandidat.

Turleder: Geograf Bent Valeur

Dato: 30. september. Tidspunkt: 11.00-15.00

\section{Draved Skov}

Draved Skov er en GeoSite-kandidat.

Turleder: Naturvejleder Søren Rask Nielsen Dato: 1. oktober. Tidspunkt: 11.00-13.00

27. Als - hvad kan man finde på stranden? Turledere: Jørn Moos og Jørgen Trelle Pedersen

Dato: 30 . september. Tidspunkt: 9.30-12.00

28. Als - få hjælp til at bestemme sommerens stenfund

Ledere: Jørn Moos og Jørgen Trelle Pedersen Dato: 30. september. Tidspunkt: 13.00-16.00

29. Blandt klimper, polde og indlandsklitter i Frøslev Plantage

Frøslev Plantage er en GeoSite-kandidat

Turleder: Skovfoged Ivan Lund

Dato: 30. september. Tidspunkt: 13.00-15.30

30. Vissenbjerg Bakker

Vissenbjerg Bakker er en GeoSite-kandidat.
Turleder: Naturvejleder Carsten O. Hansen Dato: 30. september. Tidspunkt: 14.00-16.00

31. En vandring gennem 540 millioner år, Tarup-Davinde

Turledere: Amatørgeologerne Peter Mortensen, Ole Allan Jensen, John Jørgensen og naturvejleder Carsten O. Hansen Dato: 1. oktober. Tidspunkt: 10.00-13.00

\section{Stenslibning, Tarup-Davinde} Stenmuseum

Dato: 1. oktober. Tidspunkt: 13.30-16.00

33. Besøg en stensamler og stensliber på Sydvestfyn

Dato: 30 . september og 1. oktober

Tidspunkt: 10.00-16.00

34. Klintholm: Vand/hav, bryozokalk og fossiler

Klintholm er en GeoSite-kandidat.

Turledere: Geolog Gert Laursen og Mogens

K. Hansen

Dato: 30. september.Tidspunkt: 11.00-14.00

\section{Det Sydfynske Øhav - et "druknet"} istidslandskab

Det Sydfynske Øhav er en GeoSite-kandidat

Turleder: Geolog Søren Skibsted

Dato: 30. september. Tidspunkt: 10.00-13.00

\section{Ristinge Klint}

Ristinge Klint er en GeoSite-kandidat. Turledere: Naturvejleder Marianne Krag Petersen og Claus Dalskov

Dato: 1. oktober. Tidspunkt: 13.00-15.00

37. Strandsten og sandflugt. Fra Tisvildeleje til Arresø

Turledere: Geolog Niels Hald og biolog Jens Prom

Dato: 1. oktober. Tidspunkt: 11.00-16.00

\section{Besøg i Gammelrand Grusgrav}

Turledere: Finn Hemmingsen og Mogens Hansen

Dato: 1. oktober. Tidspunkt: 10.00-13.00

39. NV-sjællands geologi - Store og Lille Åmose samt Tissø

Åmosen er en GeoSite-kandidat

Turledere: Geologerne Nanna Noe-Nygaard og Mikkel Hede

Dato: 30 . september. Tidspunkt: 10.00-16.00

\section{Rundvisning i Geologisk Museums} nye udstilling om Solsystemet Rundviser: Geofysiker Henning Haack Dato: 30. september. Tidspunkt: 14.00-15.00

\section{0a. Geologisk Museum}

Dato: 30. september og 1. oktober

Åbent: $13.00-16.00$

\section{Find forsteninger på Saltholm}

Turleder: Hans Kloster

Dato: 1. oktober. Tidspunkt: 10.00-16.00 
42. Kan der findes flere dinosaurfodspor i Danmark?

Foredragsholder: Geolog Jesper Milan Dato: 1. oktober. Tidspunkt: 14.00-16.00

43. Stevns Klints geologi - så går vi i dybden Stevns Klint er en GeoSite-kandidat. Turleder: Naturvejleder Peer Nørgaard Dato: 1. oktober. Tidspunkt: 13.00-16.00

\section{Stevns Klint og dinosaurerne}

Stevns Klint er en GeoSite-kandidat. Turledere: Geologerne Bodil Lauridsen og Tove Damholt

Dato: 1. oktober. Tidspunkt: 13.00-15.00

45. Den verdensberømte Stevns Klint Stevns Klint er en GeoSite-kandidat. Turleder: Geolog Morten Bjerager Dato: 30. september. Tidspunkt: 10.00-12.00

\section{5a. Stevns Museum}

Dato: 30. september. Åbent: 11.00-17.00

46. Fakse Kalkbrud - af international betydning

Fakse Kalkbrud er en GeoSite-kandidat. Turleder: Vagn Aage Andersen

Dato: 30. september. Tidspunkt: 14.00-16.00

46a. Fakse Geologiske Museum

Dato: 30. september. Åbent: 14.00-16.00

47. Dobbeltkysten ved Glænø, hvad er det?
Turleder: Kurt Kjær

Dato: 30. september. Tidspunkt: 13.00-17.00

48. Sten, fossiler og mineraler - udstilling i Næstved

Fremviser: Hans-Henrik Meyer

Dato: 30. september. Tidspunkt: 10.00-14.00

49. Lær strandens sten at kende på Enø Turledere: Torbjørn H. Madsen og Finn Madsen

Dato: 1. oktober. Tidspunkt: 10.00-14.00

50. Møns Klint - lyden af stilhed

Møns Klint er en GeoSite-kandidat. Turledere: Nils Natorp og naturvejleder Katrine Gro Larsen

Dato: 1. oktober. Tidspunkt: 11.00-16.00

51. Sten og fossiler i Danmarks Traktormuseum på Falster

Dato: 30. september. Tidspunkt: 11.00-16.00

52. Sten og fossiler på Falster

Udstiller: Peter Bennicke

Dato: 30. september og 1. oktober

Tidspunkt: 13.00-17.00

53. Kul, dinosaurer og vulkaner i Skåne Turleder: Geolog Erik Schou Jensen Dato: 1. oktober. Tidspunkt: 08.00-19.00

54. Besøg i Sorte Gryde på Bornholm Turleder: Martin Holm
Dato: 1. oktober. Tidspunkt: 12.00-18.00

\section{Læsåstiens geologi}

Lokaliteten er en GeoSite-kandidat.

Turleder: Geolog Hans Peter Birk Hansen

Dato: 30. september. Tidspunkt: 10.00-13.00

\section{NaturBornholm}

Dato: 30. september og 1. oktober

Åbent: 10.00-17.00

\section{Yderligere info}

Geologiens Dage 2006 koordineres af Den Danske Nationalkomite for Geologi i samarbejde med Skov- og Naturstyrelsen, Geologisk Museum København, Danmarks og Grønlands Geologiske Undersøgelse og Geologisk Institut på Aarhus Universitet. De enkelte arrangementer gennemføres af en række foreninger, museer og naturcentre med videre.

Yderligere oplysninger om turene kan findes på www.naturnet.dk. Brug søgeordet "Geologiens Dag" i fritekst-rubrikken. Her findes også kort med præcis angivelse af mødested. Den foreliggende oversigt kan rekvireres hos Skov- og Naturstyrelsen eller hos GEUS.

Information om Geologiens Dage: Lise Holm, SNS: LHO@sns.dk Ole Bennike, GEUS: obe@geus.dk 